\title{
Women in Higher Education and Academia in Iran
}

\author{
Ladan Rahbari \\ Department of Languages and Cultures, Faculty of Arts and Philosophy, Ghent University, Belgium
}

Copyright $(2016$ by authors, all rights reserved. Authors agree that this article remains permanently open access under the terms of the Creative Commons Attribution License 4.0 International License

\begin{abstract}
This article addresses women's contemporary position in academia in Iran. By systematically reviewing available academic and official databases on women's positions in academia published online or in print, the question is raised if women's current position and role in academia is the result of personal choice making or an existent systematic discriminatory social structure. To address this issue, available Iranian research and data on female recruitment in universities are analyzed. The results show that there is a general accordance on two findings in the research addressing women's position in academia. First, gender discrimination is restricting women's choices by systematically excluding them from educational, managerial and administrative positions. Second, in spite of the substantial increase in women's enrolment in tertiary education, significant development in women's position and role in scientific and educational institutions has not taken place. After discussing the data, I will try to compare two sets of sociological theoretical approaches that offer explanations for women's lower levels of participation in the academia; namely, theories of exclusion and theories of participation. I suggest that the former is more effective in analyzing women's position in Iranian academia, because of being based on recognition of the existing structural discriminations. Although women's participation in higher education is gradually growing and gender boundaries are being stretched on a daily basis, there is need for fundamental structural changes in social and educational spheres, and widespread implementation of positive discrimination.
\end{abstract}

Keywords Academia, Discrimination, Education, Gender, Iran, Participation, University

\section{Introduction}

For centuries, women have been excluded from the academia and scientific production due to their gender in many societies worldwide. Women's current situation in academia is a result of dominant patriarchal social, cultural and political structures that have systematically excluded them from knowledge production and education. The existence of gender-based public-private sphere binary segregation has long made women's status unstable in many social public roles and careers including academic ones.

The history of educational roles shows that women have been a small minority in educating adults until the $20^{\text {th }}$ century, while as Tamboukou [32] explains, teaching children has long been considered to be in the middle of public-private continuum and thus more appropriate for women. Anthropologist Sherry Ortner [29] had similarly noted that women's position in the society is perceived to be between the natural and the cultural. Women have thus been considered as performing the linkage between culture and nature, because they train and nurture natural beings, namely infants, and help them develop in to cultural beings as adults. Although women are eligible to teach, their role is bounded to teaching young non-adult trainees. Women's role in educating young children is linked to their 'natural' role as mothers [32].

Educating and empowering girls and women and making use of their capabilities and leadership capacities in the economic, political and social spheres is proven to be fundamental for succeeding to reach high levels of development [31]. There is literature, especially in human rights and development areas discussing why and how women in the Global South have had lower status in educational roles, and in production of science and different forms of knowledge, compared to men [24, 21].

This claim is almost equally valid in many societies in the Global North. Historical evidence shows that in both Asian and European countries, between eighth and nineteenth century, there was a common idea of femininity that was considered to be in contradiction with education and mental activity [22]. This ideology was partly rooted in Aristotelian ideas of gender inequality. Many intellectuals such as Rousseau, Kant and Comte believed that women were anatomically unable to conduct mental activity as well as men [3]. In Early nineteenth century European constitution passed a law to prohibit any kind of formal training for women, except domestic chores and virtue courses, in order to protect the familial union [9]. In pre-nineteenth century Europe women had four choices of life: marriage and wifehood, becoming a nun, a maidservant or a prostitute [18].

Iranian women's choices were the same as three of the 
choices of the European women; but due to the emphasis on marriage in the cultural and religious discourse of sexuality, they could not avoid marriage as Christian nuns did; a woman's existence was highly defined by her bound to male relatives especially her father and her husband. In both societies, women's education was limited to reading religious texts, learning ethical-cultural female virtues and learning how to do domestic chores such as cooking and sewing.

Today, in many countries such as Iran, despite women's entrance in universities and other educational institutions in almost similar rates as men (and with a higher rate in many fields, especially humanities), there are relatively few women in high collegial, educational and managerial position in educational institutions such as schools and universities. While even highly developed countries such as the United States also still take steps to improve female share in education management [20], the level of female participation is still relatively lower in less developed countries.

Whether women's position and role in science is a result of their low participation or an existent discrimination is the main question addressed in this paper. To discuss this, it is essential to investigate the history of women's role and position in scientific work. After doing a brief historical inquiry, I will be focusing on available data about universities and educational institutions in order to investigate women's current position and role in Iranian academia.

\section{Method}

This research is based on systematic review of data derived from historical documents, official archives, websites, academic research, and books. Systematic review is referred to a method of reviewing with the scope of providing a summary description and combination of the results in a field of study, sometimes followed by re-analyzing them; if the re-analysis is included in the research, the systematic review becomes a meta-analysis [30].

In this research, meta-analysis was done on data on women's role and position in academia and higher education. To do this, first, possible resources such as online and printed journals and books on women and/or education have been identified. It is important to note that sociology/anthropology of science and knowledge has very recently attracted Iranian social science scholars; thus the literature on women's role and position in education is not substantial. There is also lack of anthropological and qualitative studies, as quantitative methods are highly favored in the Iranian social science disciplines [26]. To compensate for lack of academic research, I used yearly statistics provided on official website of Iranian Ministry of Science Research and Technology. This data has been used to extract percentage of female university lecturers (both tenure track and part-time lecturers), in all academic levels from 1995 to 2008. I have also analyzed two national announcements for filling university tenure track positions, published on Iranian Ministry of Science Research and Technology's official website. National announcements for hiring full-time university tenure track positions publish the names and requirements of all universities willing to hire doctorate (and sometimes master degree) graduates in all academic disciplines. The requirements also include the candidates' gender. I have also referred to the global Gender Gap Index (Iran's profile) introduced by World Economic Forum from 2006 until 2015; this index is a framework for capturing the magnitude and scope of gender-based disparities and tracking their progress throughout the years.

In the second step, resources were systematically reviewed and a summary was extracted from important results that addressed statistical or qualitative results on gender parity in education and academia in Iran. Finally, data was analyzed; this analysis will be discussed in subsequent parts of this paper, while accordance/contradictions of the approaches and findings will be highlighted.

\section{Women and Education}

There is little historical evidence available about women's (and men's) role and position in knowledge and their education in the pre-Islamic Persian territory. Several historical invasions to the Persian Empire, followed by centuries of unrest and anarchy, have destroyed a great amount of historical evidence and documents. The oral history is very much based on mythical views of Iranian ethnic identity [2] and thus, is relatively unreliable source of historic data; more consistent and reliable evidence is however available since around sixteenth century, the onset of Safavid dynasty's ruling in Persia. The Safavid ruled Persia from 1501 AD to 1722 AD. During this period, science and technology made great progress and as historical records show, there were women who contributed in scientific work by writing books, teaching and founding libraries and mosques [27] and left a significant influence in some disciplines. However, there were no official institution to educate women and the few exceptions of female accomplishment were women whose male relatives (husbands, fathers...) were among scarce intellectual elite who believed in the social advantages of educating women. Despite the expansion of fields of knowledge, during the whole Safavid period, there were only a few female scholars who had impact on knowledge production, since women's presence in the public sphere was extremely limited [13].

After the Safavid Empire's collapse, there came some decades of anarchy and civil war until Qajar dynasty took over the throne in late eighteenth century. Qajars were monarchs who were under heavy influence of western culture and were interested in modernizing the society. They founded Dar Al-Fonun which was one of the most important events in Persian history of education. Dar Al-Fonun was a modern only-male college to train upper-class Persian youth 
in Medicine, Engineering, Military Science, and Geology. The first formal education system for women in Iran was founded at 1848 by the Qajar 'reformist' king Naser-Al-Din Shah [1]. However, this formal education was not general and it only covered a small section of the society which included mostly rich or noble families' children.

General schooling system for women started later in 1912 [22]; however, its development and extension throughout the country took place very slowly due to inefficient management of monarch administrators, internal state problems and foreign interference in internal national affairs. Iranian women's education started to expand since 1950s during the Pahlavi dynasty. Pahlavi's westernization project started by the first Pahlavi included women's participation in the society but was highly criticized for being incompatible with Iranian context of the time by challenging people's religious and cultural beliefs [37]. Despite the criticism, during and since the Pahlavi era, the literacy rate has constantly been growing, starting since 1956 and continuing after the Islamic revolution until today. Women's literacy rate grew 22 percent from 1986 to 1996 and reached 80.34 in 2006 [17]. It is estimated that literacy rate was 81 percent for women and 89 percent for men in 2012 (with a sex ratio of 0.90 ) ranking the country in the $100^{\text {th }}$ position, among 132 countries [10]. In 2015, according to UNESCO estimations, the Iranian adult male literacy was expected to be 93.6 percent, while female adult literacy was expected to be 87.6 percent [35].

In Iran, women's university and college education was delayed until the last decades of twentieth century; while in Western countries, for instance in England, first woman entered university in 1893, and in the United States universities such as Chicago, Cornell and Berkeley started to accept female students in 1890s [3]. Since the Iranian Islamic Revolution of 1979, women's enrollment rate in tertiary education has grown gradually. According to data provided on UNESCO, women's enrollment in tertiary education was 51 percent in 2005; while in 2007 the same ratio was 72 in Canada and 70 in the United Kingdom. While this increase has positive effects on women's position in the academia and in the society, it relies on highly quantitative findings and statistics of participation. It is also important to note that reports of female participation rates do not reflect existing inequalities; for instance, in 2012, world economic forum declared that Iran ranks $101^{\text {st }}$ in 'educational attainment parity' score among 135 countries. Educational attainment parity index is a combination of female literacy and female enrolment in various levels of education [10], compared to their male counterpart. This rank shows that despite having made progress through a more equalitarian educational system, comparing with other countries, Iranian women's right to equal education has not yet been realized.

Studying on women's contemporary position in universities in Iran has started in the 1990s. Studies on this subject have univocally suggested that women do not make up a substantial work force in Iranian universities. A study conducted by Zahedi [34] has focused on women's participation and share of positions in three major universities in Iran's capital city, namely, Tehran University, Shahid Beheshti University and Allame Tabatabayi University. This research had two important results; first, female academic position rates are relatively low; second, gender-based discrimination is a defining factor in the election of eligible candidates for open academic positions. This situation has not seen great change since Zahedi conducted that study. Mahdavi and Latifi's [19] study in all Iranian public universities in 2009 shows that from an overall amount of 79617 university tenure track position holders, only 18.25 percent are female and 81.75 percent are male.

In the next sections, I will portray women's contemporary role and position in Iranian universities from two different aspects. First, I will discuss women's scientific position by referring to their role in lecturing, writing articles/books, researching, and membership in scientific committees. Then, women's role in executive and leadership positions, such as membership or directing, and administrative roles such as managing collegial associations and universities will be investigated.

\section{Women in Academic Positions}

In this section, women's participation in the academia is illustrated by their role as holders of academic positions. $B y$ academic position, I refer to positions such as tenure track professors, part time lecturers, academic council members, academic-scientific journal referees, writers and members.

\subsection{Women in Teaching Positions}

In the last few decades women in Iran have appropriated a higher university entrance rate than men. In a quantitative study, Tavakkol, Yegane and Sadati [33] have studied overall university entrance sex ratio in ten years from 1993 to 2003. They showed that 68 percent of all bachelor's degree, 52 percent of master's degree and 35 percent of all doctorate degree entrants of all academic disciplines in Iranian universities have been female students during this period. Male to female sex ratio is thus, obviously going up by moving to higher levels of education; meaning that women have more access to lower levels of higher education. This finding is more significant when it is compared to male to female sex ratio in academic positions such as university tenure track positions. Javaheri and Dariapour [16] reported that women's participation percentage as university tenure track positions in eight provinces of the country ranges between 4.3 percent of all university tenure track positions (in the northern province of Mazandara) to 11.3 percent (in the southern province of Fars).

The average number of university tenure track positions in these eight provinces (including Mazandaran, Azerbaijan, Esfahan, Gilan, Hamedan, Khuzestan, Gilan, and Fars) is 8.2 percent, which is low comparing to the average 35 percent 
female graduation in the doctorate level from the universities. This means that, men holding a doctorate degree have a significantly higher chance of getting hired as university tenure track position holders compared to their female counterparts.

There is also evidence showing that women's situation in scientific positions is not improving. Zahedi's [33] study, in three major public Iranian universities from 1991 to 2001, showed that women's share in tenure track positions has not significantly grown in the ten years preceding her study. She has reported that women's share in the faculties has changed 1.41 percent in Tehran University, 2.7 percent in Shahid Beheshti University and 0.6 percent in Allame Tabatabayi University. This finding suggested that there is no homogeneity in female university tenure track position percentages in different universities/cities; it also partly implied that no nationwide effective long-term plan was exerted to empower women in the academia and scientific arena.

\subsection{Women as Part-time Lecturers}

In order to provide a clearer image of women's situation in teaching positions of higher education, I extracted yearly statistics provided on official website of Iranian Ministry of Science Research and Technology have been used and percentage of female university lecturers (both part-time and tenure track positions), in all academic levels from 1995 to 2008. Analysis of this database shows that women's share has oscillated between the maximum of 18.78 percent of all lecturers in the academic year 2002-2003 and 10.65 percent in the academic year 2007-2008. Comparing the average percentage of 8.2 female tenure track position holders in 8 Iranian provinces with the average percentage of 17.10 female lecturers (both tenure track position holders and part-time lecturers) indicates that female graduates are more likely to have a temporary position in universities than a permanent position as university tenure track position. Despite the great number of female doctorate graduates, universities avoid hiring full-time female graduates in disproportionate numbers. While women have a higher chance of working part-time, the sex ratio in part-time lecturing positions is still unbalanced, with higher male participation rates.

To further test the validity of this conclusion, two national formal announcements (2011 and 2012) for filling university teaching positions which were published on Iranian Ministry of Science Research and Technology's official website have been reviewed. In 2011, national announcement for hiring full-time university tenure track positions published the names and requirements of all universities willing to hire doctorate graduates; in this announcement 16.50 percent of universities declared that they would hire only male graduates in the requirement section, despite having no official or state implemented limitations to accept female doctorate graduates. This trend was repeated in 2012, when again 15.22 percent of universities omitted female doctorate applicants at the very onset of the evaluation process without explaining the underlying logic of such a widespread exclusion based on gender. It is important to note that these universities, which excluded female candidates of teaching positions from applying for vacancies, accepted male and female students.

Mahdavi and Latifi [19] have investigated several factors' impact on female university tenure track position holders' academic upgrade. They indicated that scientific work, achievements and experience explain their upgrade with a 0.23 beta coefficient in multivariate regression analysis; this result means that other factors apart from scientific excellence and achievements are intervening in women's academic upgrade.

\subsection{Women as Researchers and Academic Council Members}

While rates of hiring female lecturers highly rely on structural factors and political decision making and environments of educational institutions, and as indicated in the previous sections, female candidates have not been favored in Iranian academia, there are women who have resisted the obstacles and reached teaching or researching positions. Despite all existing limitations, and despite the unchanging rate of female academicians in universities, there is evidence that women's share in individual research and publishing has expanded. Zahedi [33] has reported changes in women's share of scientific publications between 1991 and 2001 in three major universities. These findings indicate that women's share in book and article publishing has grown from 12.1 percent of all publications in 1991, to 45.4 percent in 2001; women's share in conducting research projects has grown 27.4 percent in 1991 to 58.1 percent in 2001.

This is a very significant finding, since it indicates that women are actually in possession of high capacities to reach academic achievements; and despite being in minority in the academic realm and encountering structural limitations, their endeavor to reach better academic and educational status is salient.

Studies on women's share in academic councils also show that women are in minority in these councils. Ezazi [6] has studied women's involvement in three Iranian sociological journals. She has shown that women have a relatively low involvement in peer-reviewing of articles (11 percent) and in scientific committees (4 percent) and only 12 percent of published articles are written by a woman as the first writer.

Women's low rate of membership in scientific councils and associations seems to be a universal problem. In 2002, approximately 10 percent of all full-time members of 20 scientific academies in the world were female and this rate is nearly 4.4 in Nobel Prize organization [14]. Goulden, Mason and Frasch [8] have discussed that although female students are in majority in many disciplines such as social sciences and psychology, scientific organizations and institutions are still selecting their members based on traditional gender ideologies. 


\subsection{Women in Executive Positions}

Women's lower degree of presence in leadership and management positions is a universal problem. United Nations has reported that in year 2000, women were holding 30 percent of work force in administrative and executive jobs in all categories [16]; while in Iran according to World Economic Forum yearly report of 2012, female legislators, senior officials and managers hold 13 percentage of the whole existing positions ( 0.15 female to male sex ratio), ranking the country 97 th among 132 countries worldwide [10].

In the realm of higher education, Iranian public universities have never had a female University Rector except for single-gender education universities which accept only female students [19]. Lack of women in universities' managerial and leadership positions seems to be universal, as in 2010 , only 7 percent of all universities worldwide had a female Rector [33]. Zahedi [34] has investigated women's position in high university committees, boards of directors and other managerial positions from 1991 to 2001. She has indicated that not only women have little share, but also in the duration of ten years no significant change has taken place (2 percent).

Female scholars believe that cultural beliefs are the most effective obstacle impeding their promotion to high academic levels and managerial positions; they also believe that sexual discrimination is the result of existing patriarchal ideology [34] from which the academia is no exempt from. Hoseini, Saeedi and Salehi [11] have used logistic regression in a sociological study which tried to estimate women's luck for acceptance in a managerial position. They concluded that there was no correlation between women's administrative capabilities and their election for such positions. There is much evidence to support the hypothesis that women are facing external cultural and structural obstacles to reach high positions in the academia; for example, there are also indications in the literature which show that culturally defined stereotypes have impacted women's willingness to achieve high positions. Tavakkol, Yegane and Sadati [33] have investigated the correlation between patriarchal socialization and women's tendency to enter higher studies and hold administrative positions; they indicate that women who believe in gender stereotypes and traditional female roles are less likely to volunteer for such positions [33].

\section{The Gender Gap}

Most studies mentioned in this article have demonstrated that women have been struggling to reach their rightful positions in a gendered hierarchical structure in the academia. An appropriate complementary analytic tool to show the gender differences in the educational system is the Global Gender Gap Index introduced by World Economic Forum which is a framework for capturing the magnitude and scope of gender-based disparities and tracking their progress [10].
The gender gap index seems appropriate because it focuses on measuring gender gaps rather than levels; it captures gaps in outcome variables rather than gaps in means or input variables; and finally, it ranks countries according to gender equality rather than relying merely on women's empowerment statistics. World Economic Forum's report of gender gap index usually includes more than 130 countries around the world in its results, including Iran. This report shows that Iran's gender gap which consists of gender inequality in four spheres of economy, politics, health and education have not changed dramatically between 2006 and 2015. Iran's gender gap in political empowerment and economic participation is much lower than its rank in educational attainment, still, in the case of educational attainment Iran's rank is fairly low $\left(80^{\text {th }}\right.$ among 115 countries in 2006 and $106^{\text {th }}$ among 141 countries in 2015) since women make up a low percentage of the senior and highly skilled positions.

\section{Discussion}

In the beginning of this article the main question of the paper was defined as 'are women's position and role in academia a result of their low individual participation or an existent discrimination?' To respond to the question, based on the existing data presented in the previous sections, I discuss two sets of possible theoretical frameworks suggested by Janalizade, Moghimi and Amini [14].

There have been several explanations suggested in the framework of several sociological theories to explain women's current position and role in science and education. Two categories of sociological theories have been recognized by Janalizade, Moghimi and Amini [14], namely Participation theories and Exclusion theories, which will be used to answer the main question. Janalizade, Moghimi and Amini [14] have reviewed sociological literature on women's role in scientific work in Iranian scientific journals; they have recognized these two categories of studies on women's participation in science and knowledge production and higher education institutions. First category studies women's participation in knowledge production and its socio-cultural consequences; this group adopts an individualistic approach to participation which leads to considering women free agents who make choices that result in their lower participation in the academia; while, the second category, exclusion approach, which consists of a smaller portion of literature focuses on unequal shares and gender discrimination and exclusion of women from scientific institutions.

There are several social theories claiming or resulting in the understanding that women's low participation is not the result of social, cultural or political structures but the natural direct or indirect outcome of their sexuality. Difference theory and role conflict theory are among these explanations. Difference theory explains that women are unable to reach the same positions because of their inherited natural traits 
that are different from men's. Similar to how Lawrence H. Summers, University of Harvard's chief administrator declared in a speech in 2005, that women's contemporary position could be the result of essential differences between men and women [14], difference theory, by ignoring socio-historical impact, not only fails to explain gender equality in many countries such as Iceland [10], but also fails to explain the enormous change of women's position in science and education achieved throughout the history.

Role conflict theory explains that due to having different innate roles, women and men must act in the framework of their pre-determined roles. According to this approach, gender roles are inevitable (not necessarily the biological, but social and cultural sense) and conflicts arise when gender boundaries are violated [15]. Researchers who works in the framework of this theory take for granted the highly gendered divisions of social roles and labour. The policy implications offered by this approach are also naturally in line with the existing gendered social settings. This theory at best guide women to manage the existing inequalities better; for instance, in the context of Iranian academia, Qaem and Nurayinejad [25] have provided some solutions and time management tips for women in higher education who are facing problems dealing with household chores and their job responsibilities. This theory obviously ignores the cultural foundations of gender role divisions, falling into biological or cultural essentialism.

Second category is the exclusion framework which consists of theories which put emphasis on the existence of socio-cultural, economic and political structures which have created obstacles against women's inclusion in knowledge production, distribution and use. These theories adopt a more critical approach and propose that changing current situation is only possible by challenging and finally removing these structural obstacles. Javaheri and Dariapour [16] for instance, suggested that gender ideology of patriarchal system is the bedrock of all sexist discriminations and attitudes, and for this, the first step to eliminate educational inequality and any other kind of gender-based inequality is to question and work against patriarchal ideology.

Gender ideology is the source of much formal discrimination against women. Esfidani [4] has discussed that many university administrators and policy makers in Iran (and elsewhere), hold patriarchal stereotypes and do not believe women can be effective in leading positions; to change this ideology, it is essential to begin the change in socialization processes in effective ways. As long as the education system is deeply based on promoting binary gender differences, it will be difficult to create real change in women's position. Forutan [7] has studied elementary school books and teaching system and criticizes it as an internalization mechanism of sexist ideology; having conducted content analysis on elementary school books, his [7] findings showed that public - private binary system of gender roles is reproduced and represented in elementary school books' textual and visual content. Shahtalabi, Yarmohammadian and Ajami [28] have also studied factors effecting women's success in academic sphere; they demonstrated that women in academic positions are not only affected by their family members' and friends' ideas, but also by collegial managers' sexist ideology.

There is also evidence showing that there is an official exclusion process at work for both accepting female students and recruiting female university graduates in academic positions. It is reported that 40 academic fields, including engineering and mathematics, in 20 universities have started to accept exclusively male students since 2011 [5].

The gap between female graduates of higher education and female lecturers along with yearly amount of official exclusion of female applicants of university tenure track positions show that the second category of theories, namely the exclusion theories are more applicable in analyzing women's role and position in science and education in Iran.

\section{Conclusions}

In this article I discussed women's position in the academia and in higher education by analyzing academic research and official database of academic and managerial positions and roles of women, female recruitment rates in universities and national and international ratios and indexes. It is now possible to address the main question raised in the beginning of this article, 'are women's position and role in academia a result of their low individual participation or an existing discrimination?' Systematic review and analysis of the data on female inclusion and recruitment in universities compared to more individualistic practices such as publishing shows that women are actively engaged in the production of knowledge where they do not encounter official structural limitations. There is general accordance on two findings. First, gender discrimination is restricting women's choices by systematically excluding them from educational, managerial and administrative positions. Second, in spite of the substantial increase in women's enrolment in tertiary education and the great increase in the number of female graduates in higher degrees of education, due to the existing structural obstacles, a significant change in women's position and role in the academia and higher education has not taken place.

This research also reported substantial evidence that Iranian higher education institutions effectuate gendered hierarchy and power distribution and practice gender discrimination in filling available academic and administrative positions. Cultural-historical ideological system of patriarchy is reinforced and reproduced in universities; thus the most effective theoretical tools to analyze women's lower levels of presence in the academia are theories of exclusion, which are based on the recognition of a structural gender-based discrimination system; such explanations can be found in social learning or feminist theories.

This article provided a widely descriptive and historical analysis of the nature of gender discrimination in scientific 
institutions in Iran. It also aimed on proposing effective theoretical tools to further study women's position in academia and higher education. It is important to note that this article does not claim or conclude that positive change is not happening or that women have had no share in the process of knowledge production in Iran; in fact, women's participation in higher education is gradually growing and gender boundaries are being stretched on a daily basis. The issue of gender-based discrimination in the academia and higher education is attracting more attention in the Iranian social science inquiry, and awareness is rising among scholars; but there is also need for structural changes in social and educational spheres, and widespread implementation of frameworks and settings seeking gender equality.

\section{REFRENCES}

[1] Abrahamian, E. (2008). A History of Modern Iran, London: Cambridge University Press.

[2] Ahmadi, H., Mahmoodi, A. (2015). Myth, National Identity and Iranian National Attitude towards International Relations (in Farsi), Iranian Review of Foreign Affairs, 5(4): 71-90.

[3] De Jardins, J. (2010) the Madame Curie Complex, New York: Feminist Press.

[4] Esfidani, M.R. (2002). Obstacles of Achieving Managerial Positions (in Farsi), Iranian Journal of Research on Women, 9 , $67-85$.

[5] Etemad Journal (No writer) (2012, August 26) Gender Divisions Continue in Universities (in Farsi), p. 13. http://www.magiran.com/npview.asp?ID=2547763

[6] Ezazi, S. (2009). Women's Role in Sociological Journals (in Farsi), Iranian Journal of Research on Women, 4, 86 - 111.

[7] Forutan, Y. (2010). Sexual Socialization in Iranian School Books (in Farsi), Iranian Journal of Women in Development and Politics, 8(216), 3-195.

[8] Goulden, M., Mason, M.A., Frasch, K. (2011). Keeping Women in the Science Pipeline, the annals of the American Academy of Political and Social Science, 63, 141- 162.

[9] Groult, B. (2000). Women from Men's Point of View (in Farsi), translated to Farsi by M.J. Pouyande, Tehran: Jaam Publication.

[10] Hausmann, R., Tyson, L.D., Bekhouche, Y., Zahidi, Z. (2012). The Global Gender Gap Report 2012, Geneve: World Economic Forum.

[11] Hoseini, M., Saeedi, A. Salehi, J. (2007). Effective Factors on Women's Participation in University Administration: A Logistic Model (in Farsi), Iranian Journal of Women's Studies, 1(3), $127-141$

[12] Iranian Center of Research and Planning Higher Education (n.d.), Statistics of Higher Education, Retrieved November 3, 2012, from http://www.irphe.ir/FA/Statistics/Gozide_kadr.as $\mathrm{px}$
[13] Jahandideh, Mitra; Khaefi, S. (2011). Women's Status during the Safavid Period, Recent Researches in Social Science, Digital Convergence, Manufacturing and Tourism, 137-142. http://www.wseas.us/e-library/conferences/2011/Lanzarote/S OSOMACTS/SOSOMACTS-22.pdf

[14] Janalizade, H. (2007). Analysis of Women's Position in Scientific Institutions (in Farsi), Iranian Journal of Research on Women, 5 (1), 173-199.

[15] Janalizade, H., Moghimi A. and Amini M. (2008). Science and Gender: Reviewing Researches in Iran and across the Globe (in Farsi), Iranian Journal of Higher Education, 3: 83-102.

[16] Javaheri, F., Dariapour, Z. (2008). Female University Lecturer's Career Problems (in Farsi), Iranian Journal of Research on Women, 6(2), 79-106.

[17] Khazali, A. (2010). Iranian Women after the Islamic Revolution, Beirut-London: Conflict Forum.

[18] Laven, M. (2003). Virgins of Venice: Enclosed Lives and Broken Vows in the Renaissance Convent, London: Penguin Books.

[19] Mahdavi M.S., Latifi, R. (2009). Sociological Study of Female Tenure track position Holders' Upgrade in Central Azad University of Tehran; Problems and Solutions (in Farsi), Iranian Journal of Social Science Inquiry, 3(3), 7-22.

[20] Martin, J. L. (2011). Women as Leaders in Education, Santa Barbara, California: Praeger.

[21] Mena Development Report (2004). Gender and Development in the Middle East and North Africa Women in the Public Sphere, Washington: The International Bank for Reconstruction and Development /The World Bank, http://web.worldbank.org/archive/website01418/WEB/IMA GES/281150PA.PDF

[22] Najmabadi, A. (2005). Women with Mustaches and men Without Beards: Gender and Sexual Anxieties of Iranian Modernity, California: University of California Press.

[23] Official Website of University Tenure track position Recruitment, Recruitment Announcement of the Ministry of Science Research and Technology, Retrieved November 6, 2012, from http://jazb.msrt.ir/sites/

[24] OHCHR (n.d.). Fact Sheet No.23, Harmful Traditional Practices Affecting the Health of Women and Children, http://www.ohchr.org/Documents/Publications/FactSheet23e n.pdf

[25] Qaem, M.M., NurayiNejad, M. (2010). Qualitative Study of Internet's Role in Women's Personal and Professional Life (in Farsi), Iranian Journal of Women in Development and Politics, 8(3), 31 - 55 .

[26] Rahbari, L. (2015). Peripheral Position in Social Theory: Limitations of Social Research and Dissertation Writing in Iran, Civitas, Porto Alegre, 15(1), 155-165.

[27] Riahi, M. H. (2006). Shiite Women's Role in Iranian Civilization and Culture (in Farsi), Iranian Journal of Shiite Women, 3 (10), 1999 - 236.

[28] Shahtalabi, S., Yarmohammadian, M.H., Ajami, S. (2009). Females Administrator's Experiences in Higher Education: A Qualitative Research (in Farsi), Iranian Journal of Knowledge and Research, 21, $21-40$. 
[29] Ortner S. (2006). Is Female to Male as Nature is to Culture?, in Feminism and Perspectives (in Farsi), S. Ezazi ed., Tehran: Roshangaran and Motaleate zanan Publication.

[30] Tabatabayi M., Vdadhir, A. (2010). Meta-Analysis in Social and Behavioral Science, Tehran: Jameshenasan Publication.

[31] Tambon, M; Fort, L. (2008). Girls' Education in the $21^{\text {st }}$ Century Gender Equality, Empowerment, and Economic Growth. Washington: The International Bank for Reconstruction and Development, the World Bank.

[32] Tamboukou, M. (2008). Women, Education and the Self, New York: McMillan.

[33] Tavakkol, M., Yegane M.R., Sadati, M. (2010). Sociological Study on Women's Role in Medical Education in Iran (in Farsi), Iranian Journal of Women in Development and Politics, 8(4), 27 - 50.
[34] Zahedi, H. (2002). Changes in the Position of Academic Women in One Decade (in Farsi), Iranian Journal of Research on Women, 1(4), 53-66.

[35] UNESCO (2012). Adult and Youth Literacy, 1990-2015: Analysis of Data for 41 Selected Countries, Montreal: UNESCO Institute for Statistics, Retrieved July 7, 2016, from http://www.uis.unesco.org/literacy/Documents/UIS-literacystatistics-1990-2015-en.pdf

[36] United Nations Educational, Scientific and Cultural Organization (n.d.), Women's Share of Tertiary Enrolment, Retrieved January 2, 2012, from http://data.un.org/Data.aspx $? \mathrm{~d}=$ GenderStat $\& \mathrm{f}=\mathrm{inID} \% 3 \mathrm{a} 76$

[37] Yazdkhasti, B. (2008). Women's Hijab from a Sociological Perspective (in Farsi), Iranian Journal of Women's Cultural and Social Council, 10(38): 37-61. 